\title{
Combination Therapy with Etilefrine and Pleurodesis for Refractory Congenital Chylothorax
}

\author{
Yutaro Tomobe ${ }^{a}$ Uiko Mizuguchi ${ }^{a}$ Akihiro Shimotakaharab \\ Naoki Shimojima ${ }^{b}$ Kaoru Okazaki ${ }^{a}$ \\ aDivision of Neonatology, Tokyo Metropolitan Children's Medical Center, Tokyo, Japan; \\ ${ }^{b}$ Division of Surgery, Tokyo Metropolitan Children's Medical Center, Tokyo, Japan
}

\section{Established Facts}

- Severe congenital chylothorax is refractory to conventional treatments, such as pharmacotherapy, pleurodesis, and surgery.

- Etilefrine is reportedly an effective treatment for postoperative chylothorax in children and adults.

\section{Novel Insights}

- Etilefrine may be a novel, alternative treatment for refractory congenital chylothorax in neonates when combined with other treatments.

\section{Keywords}

Congenital chylothorax $\cdot$ Etilefrine $\cdot$ Pleurodesis

\section{Abstract}

Etilefrine, a sympathomimetic agent, is reportedly effective against postoperative chylothorax. However, its effectiveness in treating congenital chylothorax was unknown. We report herein a case of refractory congenital chylothorax treated with etilefrine in a late preterm neonate with massive fetal chylous pleural effusion. The chylothorax was unresponsive to previous treatments, including dietary and pharmacological treatment and thoracic duct ligation. The pleural effusion decreased after intravenous etilefrine was begun on day of life (DOL) 84 and resolved after the addition of chemical pleurodesis with OK-432 on DOL 90. This combination therapy may be a viable treatment option for cases of congenital chylothorax that are unresponsive to other treatments. 


\section{What Is It about?}

Congenital chylothorax is often treated in a stepwise approach which includes dietary management, pharmacotherapy, and surgical intervention. We report herein a case of a preterm neonate with congenital chylothorax who was unresponsive to various conventional therapies but successfully treated with etilefrine following pleurodesis. The etilefrine regimen may provide a novel treatment option for refractory congenital chylothorax.

\section{Introduction}

Congenital chylothorax is a rare complication but a common cause of pleural effusion in neonates [1]. Severe chylothorax may cause life-threatening events, such as respiratory failure and sepsis. Its management requires a stepwise approach consisting of conservative and dietary management, the use of pharmacological agents, such as a somatostatin analog [2], and invasive interventions, including pleurodesis and thoracic duct surgery [3]. However, no standardized guidelines for treatment exist due to limited clinical evidence. Etilefrine, a less well-known sympathomimetic agent, is also a pharmacological treatment option. Recent studies have reported its use in adult and pediatric patients with postoperative chylothorax $[4,5]$. Herein, we report a case of a preterm neonate with congenital chylothorax who was successfully treated with etilefrine and pleurodesis.

\section{Case Report}

A fetal pleural effusion was detected at 29 weeks of gestation. Maternal screening for congenital infections was negative. The fetus had no apparent anomaly. Due to rapid accumulation of pleural effusion, the female infant was delivered via emergency cesarean section at the gestational age of $341 / 7$ weeks and a birth weight of 2,047 g. At delivery, the infant was intubated immediately for resuscitation. The APGAR scores were 1 and 3 at 1 and $5 \mathrm{~min}$, respectively. Bilateral chest tubes were placed immediately while in the delivery room due to severe respiratory distress. The aspirate had a clear yellow coloration. Laboratory tests of the pleural fluid revealed leucocytes $900 / \mathrm{mm}^{3}$, lymphocytes $875 / \mathrm{mm}^{3}$, total protein $22 \mathrm{~g} / \mathrm{L}$, LDH $80 \mathrm{U} / \mathrm{L}, \mathrm{Na} 140 \mathrm{mEq} / \mathrm{L}$, and K $3.7 \mathrm{mEq} / \mathrm{L}$. Based on the lymphocytepredominant cell composition, congenital chylothorax was diagnosed. Continuous drainage was begun as the first-line treatment, with as much as $170 \mathrm{~mL} / \mathrm{kg} /$ day of pleural fluid being drained. On day of life (DOL) 6, octreotide was administered at a dosage of $1.0 \mu \mathrm{g} / \mathrm{kg} / \mathrm{h}$ and gradually increased to $9.0 \mu \mathrm{g} / \mathrm{kg} / \mathrm{h}$. On DOL 13, prednisolone $2 \mathrm{mg} / \mathrm{kg} /$ day was begun. However, these treatments were ineffective and discontinued on DOL 31 and 33, respectively. Chemical pleurodesis of the left thorax with $4 \%$ povidone-iodine on DOL 51 and 55 was also ineffective. Octreotide was resumed from DOL 52. The drainage tubes were frequently blocked by viscous products, such as fibrin, and were unable to drain the pleural effusion sufficiently, resulting in deteriorating respiratory status. On DOL 70, ligation of the thoracic duct was performed but failed to decrease the drainage output, and the aspirated pleural fluid volume exceeded $70 \mathrm{~mL} / \mathrm{kg} /$ day. With the agreement of the hospital's ethics committee, intravenous etilefrine $0.5 \mu \mathrm{g} / \mathrm{kg} / \mathrm{h}$ was started on DOL 84 and increased to 1.0 $\mu \mathrm{g} / \mathrm{kg} / \mathrm{h}$ on DOL 86 . The etilefrine decreased the volume of pleural fluid, and an ultrasound examination showed decreased intrathoracic fluid. The right chest tube was removed on DOL 88. However, a small volume of fluid still continued to drain from the left chest tube. 

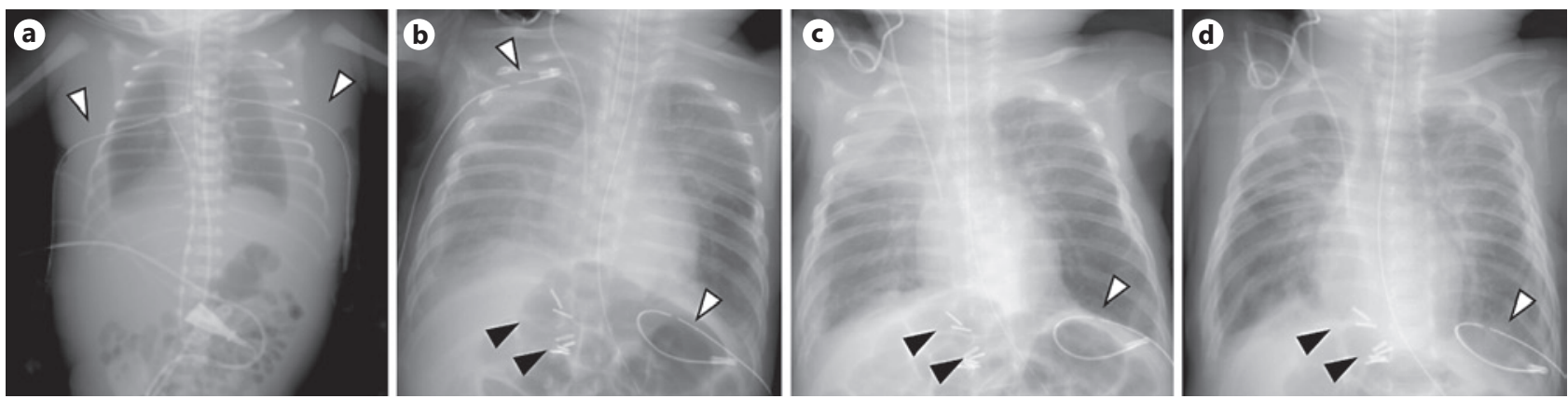

Fig. 1. Changes in chest radiograph findings after combination therapy with etilefrine and pleurodesis. White arrowheads show chest drainage tubes. Black arrowheads show thoracic duct ligation clips. Intravenous etilefrine $0.5 \mathrm{mg} / \mathrm{kg} / \mathrm{h}$ was started on DOL 84 and increased to $1.0 \mathrm{mg} / \mathrm{kg} / \mathrm{h}$ on DOL 86 . It was reduced by $0.3 \mathrm{mg} / \mathrm{kg} / \mathrm{h}$ every 2 days and eventually discontinued on DOL 112. a At birth. b On DOL 84 at the initiation of etilefrine. Chylous fluid accumulated in the bilateral thoracic cavities. c On DOL 88, pleurodesis was performed. d On DOL 96, the pleural effusion resolved.

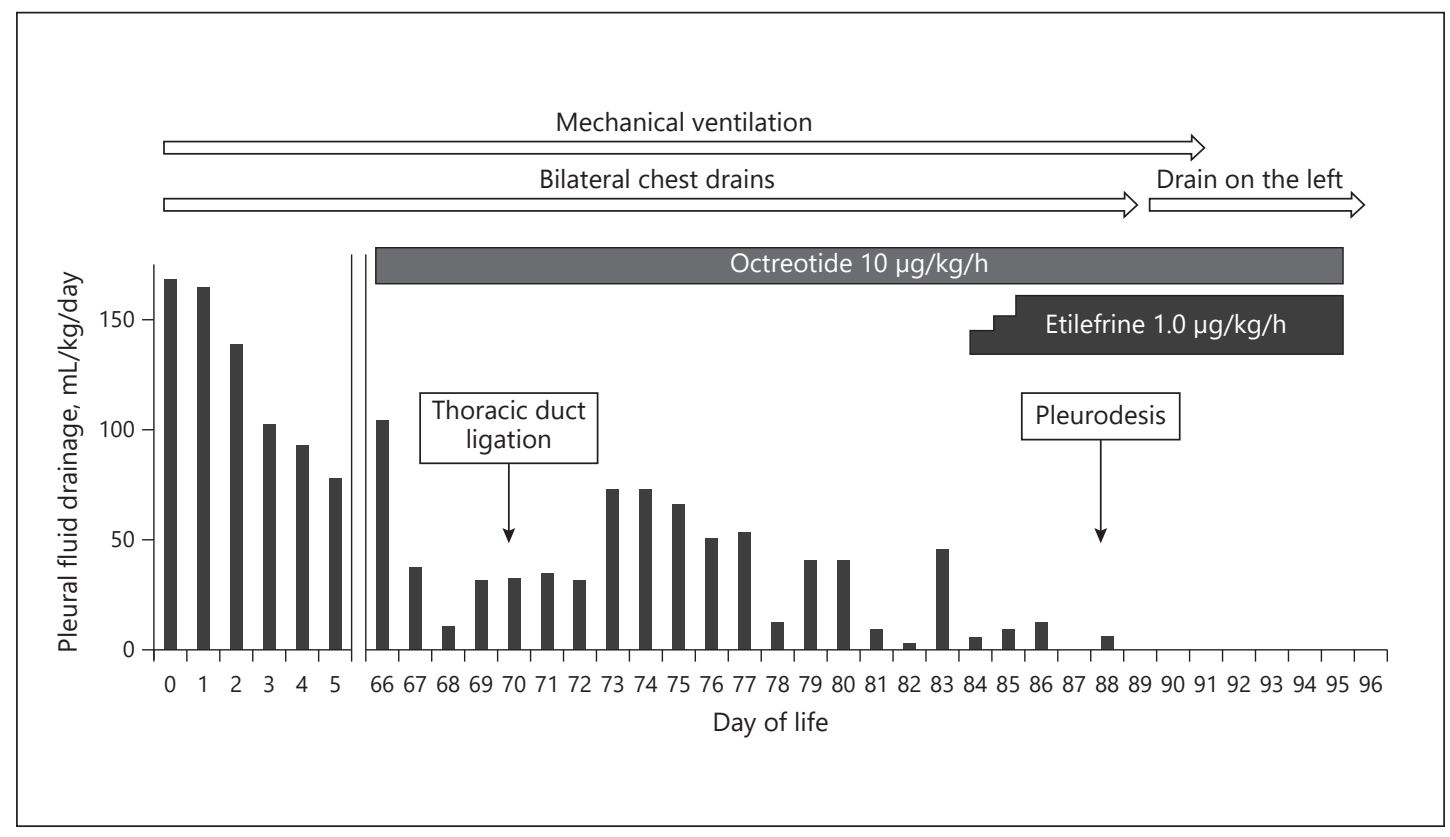

Fig. 2. Pleural fluid drainage and details of treatment. Octreotide and thoracic duct ligation were ineffective. Due to insufficient drainage, the patient's respiratory condition deteriorated. However, after starting etilefrine on DOL 84, the pooled pleural effusion decreased, and the patient became less reliant on respiratory support.

Chemical pleurodesis with OK-432 was added for the left-side chylothorax on DOL 88. The pleural effusion completely resolved on DOL 89, and the positive pressure ventilation with intubation was discontinued on DOL 91. Enteral feeding using a medium-chain triglyceride formula was started on DOL 96. The etilefrine dosage was reduced every 2 days until it was discontinued on DOL 112 (Fig. 1, 2). During etilefrine administration, no adverse events, such as tachycardia and hypertension, were noted. The infant's weight increased to 3,162 $\mathrm{g}$, and she was discharged on DOL 149. At age 8 months, she achieved catch-up growth and normal development. 


\section{Discussion/Conclusion}

We reported a case of a preterm neonate with congenital chylothorax who was successfully treated with etilefrine following pleurodesis with OK-432. Although other pharmacotherapies, pleurodesis, and thoracic duct ligation were ineffective in this case, the combination therapy finally resolved the chylous pleural effusion. To the best of our knowledge, this is the first report of etilefrine therapy for congenital chylothorax.

Etilefrine is a sympathomimetic agent stimulating both $\alpha$-and $\beta$-adrenergic receptors and is commonly used to treat orthostatic hypotension and syncope. The mechanism of etilefrine activity in chylothorax is thought to involve the constriction of smooth muscle tissue not only in blood vessels but also in lymph ducts, resulting in decreased chyle flow through the constricted thoracic duct and diminished chylous pleural effusion [6]. None of the potential adverse effects, such as palpitations, arrhythmias, and hypertension, were observed in the present case. Recently, only a few reports on etilefrine treatments have been published. Ohkura et al. [7] reported that postoperative chylothorax in 2 adult patients following an esophagectomy was successfully treated with etilefrine and pleurodesis. Muniz et al. [5] reported the resolution of a postoperative chylothorax in 2 pediatric patients with congenital esophageal atresia after etilefrine treatment. The therapeutic regimen in our case was identical to that in the latter report. Etilefrine administration was continued at a maximum of $1.0 \mu \mathrm{g} / \mathrm{kg} / \mathrm{h}$, then tapered off every 2 days if enteral nutrition increased and the pleural effusion did not worsen. As suggested above, cautious tapering of etilefrine might begin after establishing enteral nutrition, although only a few reports have used this drug in infants. Since the US Food and Drug Administration has not approved its use for chylothorax treatment, the consent of the patient's family and the ethics committee of our institution were obtained prior to treatment.

Congenital chylothorax may involve a heterogeneous clinical background, such as malformations of the lymphatic system and chromosomal abnormalities [1]. The present report importantly demonstrated the effectiveness of etilefrine in a case of congenital, non-postoperative chylothorax. Octreotide, a synthetic somatostatin analog, is widely used in the treatment of chylothorax, and its effectiveness and safety have been supported by systematic reviews [8]. However, there is no consensus on its use due to the absence of randomized controlled studies. Indeed, octreotide administration failed to reduce the chylous effusion in the present case.

The therapeutic approach for chylothorax is usually stepwise, beginning with dietary and pharmacologic management, then proceeding to invasive interventions, such as chemical pleurodesis and surgery, if needed. Our institutional protocol involves starting with fasting; if the pleural effusion decreases, enteral feeding with medium-chain triglycerides formula is then started. If it does not decrease, pharmacologic treatment, such as octreotide administration, is begun, and if that also fails, pleurodesis and surgery are considered. In the present case, the first pleurodesis was ineffective, but the second attempt including etilefrine completely resolved the pleural effusion. This difference in effectiveness was reflected in the change in chyle production. In the first trial without etilefrine, the chylous effusion volume was large. However, in the second trial with etilefrine pretreatment, the volume dramatically decreased. Further, pleural effusion continued to accumulate even after the surgical ligation of the thoracic duct, suggesting that multiple and collateral lymph ducts to the thoracic cavity had formed. Although the lymphatic etiology of the present case has yet to be fully understood, etilefrine may work by constricting the entire lymphatic flow, including the collateral circulation.

In conclusion, etilefrine combined with chemical pleurodesis was successful in treating a case of congenital chylothorax which was unresponsive to conventional management. This treatment regimen may provide a novel option for refractory congenital chylothorax.

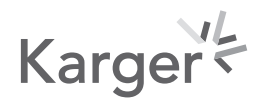




\section{Acknowledgement}

The authors thank the parents of our patient for consenting to the publication of this report. We also thank Mr. J.R. Valera for his assistance in editing the manuscript.

\section{Statement of Ethics}

The parents of the patient gave their written informed consent to publish the details of this case.

\section{Conflict of Interest Statement}

The authors have no conflicts of interest to declare.

\section{Funding Sources}

No financial support was secured for this report.

\section{Author Contributions}

Yutaro Tomobe drafted the initial manuscript and approved the final version as submitted. Uiko Mizuguchi pioneered the application of this new treatment at our hospital and approved the final manuscript as submitted. Akihiro Shimotakahara and Naoki Shimojima performed the surgery in the patient and approved the final manuscript as submitted. Kaoru Okazaki supervised the publication of this report, reviewed and revised the manuscript, and approved the final version as submitted.

\section{References}

1 Rocha G, Fernandes P, Rocha P, Quintas C, Martins T, Proença E. Pleural effusions in the neonate. Acta Paediatr. 2006 Jul;95(7):791-8.

2 Church JT, Antunez AG, Dean A, Matusko N, Deatrick KB, Attar MA, et al. Evidence-based management of chylothorax in infants. J Pediatr Surg. 2017 Jun;52(6):907-12.

3 Cleveland K, Zook D, Harvey K, Woods RK. Massive chylothorax in small babies. J Pediatr Surg. 2009 Mar; 44(3):546-50.

4 Ohkura Y, Ueno M, Iizuka T, Udagawa H. Effectiveness of etilefrine regimen for chylothorax after esophagectomy with thoracic duct resection. Esophagus. 2018;15(1):33-8.

5 Muniz G, Hidalgo-Campos J, Valdivia-Tapia MD, Shaikh N, Carreazo NY. Successful management of chylothorax with etilefrine: case report in 2 pediatric patients. Pediatrics. 2018 May;141(5):e20163309.

6 Guillem P, Billeret V, Houcke ML, Triboulet JP. Successful management of post-esophagectomy chylothorax/ chyloperitoneum by etilefrine. Dis Esophagus. 1999;12(2):155-6.

7 Ohkura Y, Ueno M, Iizuka T, Haruta S, Tanaka T, Udagawa H. New combined medical treatment with etilefrine and octreotide for chylothorax after esophagectomy: A case report and review of the literature. Medicine (Baltimore). 2015 Dec;94(49):e2214.

8 Das A, Shah PS. Octreotide for the treatment of chylothorax in neonates. Cochrane Database Syst Rev. 2010 Sep;(9):CD006388. 